Check for updates

Cite this: J. Mater. Chem. B, 2020 8,7558

DOI: $10.1039 / d 0 t b 90122 a$

rsc.li/materials-b

\section{Correction: Taking advantage of the disadvantage: employing the high aqueous instability of amorphous calcium carbonate to realize burst drug release within cancer cells}

\author{
Cheng Wang, Shaoqing Chen, Qin Yu, Fuqiang Hu and Hong Yuan*
}

Correction for 'Taking advantage of the disadvantage: employing the high aqueous instability of amorphous calcium carbonate to realize burst drug release within cancer cells' by Cheng Wang et al., J. Mater. Chem. B, 2017, 5, 2068-2073, DOI: 10.1039/C6TB02826H.

The authors regret that Fig. 2C (TEM image of PEG/OA-ACC) is incorrect due to mistakes in figure preparations. The correct version of Fig. 2 is shown below. The caption for this figure remains unchanged. It is noted that this was an honest mistake and does not affect the validity of the work and the conclusions. The authors apologise for any inconvenience caused.
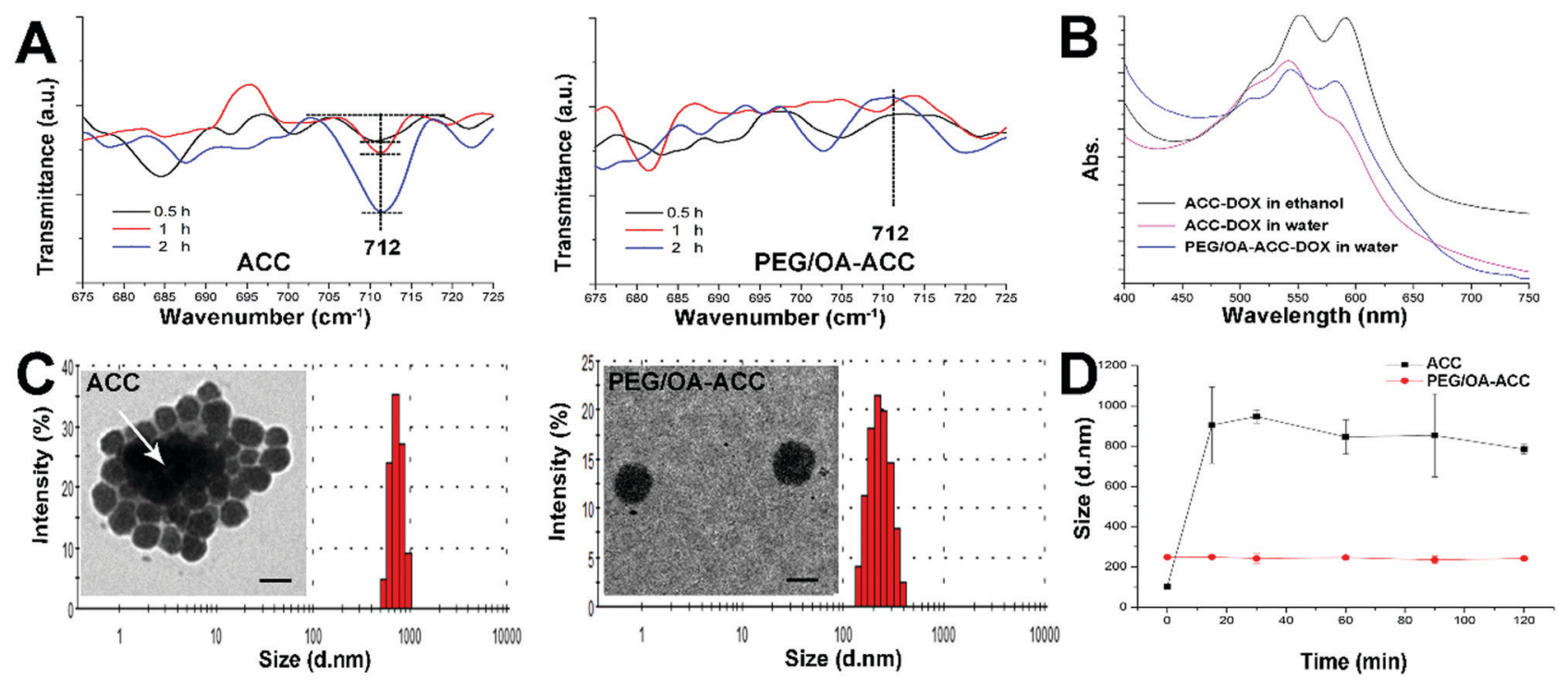

Fig. 2 Stability assays of PEG/OA-ACC. (A) Comparative FTIR spectra of ACC (left) and PEG/OA-ACC (right) incubated with water for different time intervals (0.5, 1 and $2 \mathrm{~h}$ ). (B) Comparative UV spectra of ACC-DOX and PEG/OA-ACC-DOX in different media. (C) Representative TEM and size distribution images of ACC (left) and PEG/OA-ACC (right) incubated with water. The white arrow indicates the dissolution and reshaping of ACC in water. Scale bars: $100 \mathrm{~nm}$. (D) Time dependent size change of ACC and PEG/OA-ACC in FBS. Results are expressed as mean \pm S.D. $(n=3)$.

The Royal Society of Chemistry apologises for these errors and any consequent inconvenience to authors and readers. 